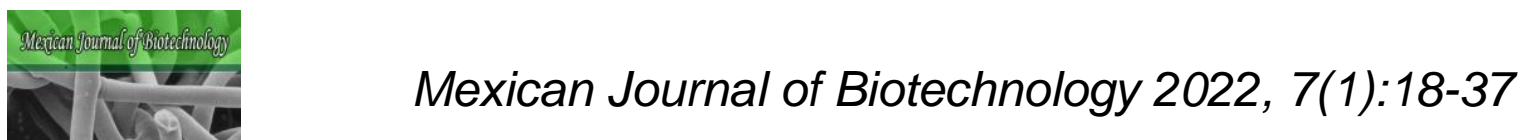

Journal homepage:www.mexjbiotechnol.com

ISSN:2448-6590

ORIGINAL RESEARCH

\title{
Prophylactic evaluation of an RNA interference (RNAi) bio-drug against White Spot Syndrome Virus (WSSV) in commercial lines of Litopenaeus vannamei broodstock
}

\section{Evaluación profiláctica de un biofármaco de ARN de interferencia (ARNi) contra el virus del síndrome de la mancha blanca (WSSV) en líneas comerciales de reproductores de Litopenaeus vannamei}

Laura Camacho-Jiménez ${ }^{1,2}$, Leobardo Montoya-Rodriguez ${ }^{3}$, Víctor Álvarez ${ }^{3}$, Saul González-Pineda ${ }^{4}$, Fernando Pino-Vera ${ }^{4}$, Claudio Humberto Mejía-Ruíz ${ }^{1 *}$

${ }^{1}$ Laboratorio de Biotecnología de Organismos Marinos, Centro de Investigaciones Biológicas del Noroeste, S. C. Calle IPN \#195, 23060, La Paz, B.C.S, Mexico.

${ }^{2}$ Comercializadora de Larvas Nauplios y Camarón S.A. de C.V. (PROLAMAR), Oscar Pérez Escobosa \#6341, 82129, Mazatlán, Sinaloa, Mexico.

${ }^{3}$ Laboratorio de Virología, Centro de Investigación en Alimentación y Desarrollo, A.C. Avenida Sábalo- Cerritos s/n, Estero del Yugo, 82112, Mazatlán, Sinaloa, Mexico.

${ }^{4}$ Biomarina Reproductiva, S.A. de R.L. De C.V. Avenida Carnaval \#720, Centro, 82000, Mazatlán, Sinaloa, Mexico.

${ }^{*}$ Corresponding author

E-mail address: hmejia04@cibnor.mx (C.H. Mejía-Ruíz)

Article history:

Received: 26 November 2021 / Received in revised form: 18 January 2022 / Accepted: / 21 January 2022 / Published online: 24 January 2022.

https://doi.org/10.29267/mxjb.2022.7.1.18

\begin{abstract}
The white spot syndrome virus (WSSV) is a constant threat for white shrimp ( $L$. vannamel) aquaculture since it can cause major economic losses. One of the biotechnologies that have gained relevance to prevent WSSV infections are the bio-drugs based on RNA interference (RNAi) mechanisms, which can be initiated by the exogenous application of double-stranded RNA (dsRNA) that is administrated to shrimp for blocking the expression of some viral gene. In the present work, we made a small-scale evaluation of a bio-drug (Bfvt) constructed from a specific dsRNA against the viral gene associated to orf89 from WSSV, as
\end{abstract}


prophylactic treatment in $L$. vannamei broodstock. The Bfvt was administrated intramuscularly to shrimp broodstock from two families ( $B$ and $C$ ) with natural resistance to WSSV, which were subsequently challenged with the virus through two ways of infection (intramuscular and per os). The results show that although both families presented a similar resistance to WSSV, the administration of Bfvt decreased the viral load and increased the survival of shrimp challenged with the virus, especially those that were intramuscularly infected. We conclude that the intramuscular administration of Bfvt is efficient and viable as strategy to prevent the WSSV infection in shrimp broodstock confined to maturation.

Keywords: Shrimp, RNA interference, prophylaxis, WSSV, broodstock, bio-drug.

\section{RESUMEN}

El virus del síndrome de la mancha blanca (WSSV) es una constante amenaza para la acuicultura del camarón blanco (Litopenaeus vannamei), ya que puede causar cuantiosas pérdidas económicas. Una de las estrategias con enfoque biotecnológico que ha cobrado relevancia para prevenir infecciones por WSSV lo constituye el empleo de biofármacos basados en el mecanismo natural del ARN de interferencia (ARNi), el cual puede iniciarse mediante la aplicación exógena de ARN de doble cadena (dcARN) que es administrado al camarón para bloquear la expresión de algún gen viral. En el presente trabajo se evaluó, a pequeña escala, un biofármaco (Bfvt) construido a partir de un dcARN específico contra el gen viral asociado al orf89 del WSSV, como tratamiento profiláctico en reproductores de $L$. vannamei. El Bfvt fue administrado intramuscularmente a camarones reproductores de dos familias $(B$ y $C$ ) con resistencia natural a WSSV, los cuales posteriormente se desafiaron con el virus a través de dos vías de infección (intramuscular y per os). Los resultados muestran que, aunque ambas familias presentaron una resistencia similar al WSSV, la administración de Bfvt disminuyó la carga viral y aumentó la supervivencia de los individuos que fueron retados con el virus, especialmente aquellos infectados intramuscularmente. Concluimos que la administración intramuscular de Bfvt es eficiente y viable como estrategia para prevenir la infección por WSSV en reproductores confinados a maduración.

Palabras clave: Camarón, ARN de interferencia, Profilaxis, WSSV, Reproductores, biofármaco.

\section{INTRODUCCIÓN}

Uno de los principales problemas que afronta la acuacultura del camarón, es la prevalencia de enfermedades causadas por virus (Arulmoorthy et al., 2000). El virus del síndrome de la mancha blanca (White Spot Syndrome Virus, WSSV) es uno de los más letales que afectan al camarón, ya que tiene una alta capacidad de replicación y virulencia, pudiendo causar la mortalidad total de un cultivo de camarón en sólo 2-7 días (Seibert \& Pinto, 2012). En camarón de cultivo, el WSSV se puede transmitir a través de la cohabitación con individuos infectados o mediate 
el canibalismo de camarones moribundos (Sánchez-Martínez et al., 2007). Por lo tanto, las células epiteliales del estómago y branquias, así como la epidermis cuticular son sitios de infección primaria (Chang et al., 1996). Sin embargo, durante el desarrollo de la infección, el WSSV también daña otros tejidos de origen mesodérmico y ectodérmico, tales como el órgano linfoide, glándula antenal, tejido hematopoyético, tejido conectivo, ovario, cordón nervioso ventral, entre otros (Shekar et al., 2012). Los signos de infección más evidentes en camarones peneidos son la presencia de depósitos de calcio en la cutícula del cefalotórax (manchas blancas), expansión de cromatóforos (coloración rojiza-café), así como anorexia y letargia (Escobedo-Bonilla et al., 2008). Una vez que los signos aparecen, la mortalidad en un cultivo de camarón puede llegar al $100 \%$ de la población en sólo 3 a 10 días (Sánchez-Martínez et al., 2007). Debido al impacto negativo de las enfermedades virales sobre la producción acuícola, es necesario garantizar la bioseguridad en las granjas de camarón, especialmente en las Unidades Productoras de Larvas (UPL), donde se produce la semilla que es utilizada en cultivos intensivos e hiperintensivos. En el caso del cultivo de camarón blanco Litopenaeus vannamei, la especie de mayor importancia comercial a nivel mundial, los stocks de reproductores para producción de larvas provienen casi en su totalidad ( 99\%) de familias domesticadas (Benzie, 2009).

Una de las estrategias más comunes para producir postlarvas libres de enfermedades, es el uso de stocks de camarón libre de patógenos específicos (SPF), los cuales son seleccionados rigurosamente a través de procesos de cuarentena multigeneracional (Alday-Sanz et al., 2018). Además, actualmente existen líneas genéticas de camarón seleccionadas por presentar cierta resistencia natural a algunos patógenos (Cock et al., 2009). Sin embargo, hasta el momento, el nivel de resistencia a WSSV mostrado por stocks selectos de $L$. vannamei no ha sido absoluto (Huang et al., 2012; Trang et al., 2019). Por lo tanto, aun cuando se utilicen reproductores certificados como libres de virus para producción larvaria, cualquier fallo en las medidas de bioseguridad al interior de las UPL pueden derivar en contaminación viral susceptible de ser transmitida horizontal o verticalmente a la descendencia (Chakrobortty et al., 2020).

Actualmente, una de las tecnologías más prometedoras para el manejo de enfermedades virales en la camaronicultura son los biofármacos basados en los mecanismos del ARN de interferencia (ARNi), que son parte de la inmunidad antiviral natural del camarón (Gong \& Zhang, 2021). La activación de los mecanismos del ARNi, tiene como resultado el silenciamiento post transcripcional de genes específicos mediado por ARNs de doble cadena (dcARNs), los cuales pueden ser sintetizados en laboratorio (Nguyen et al., 2018). Específicamente para el WSSV, genes estructurales como vp28, vp26, vp14, vp15 y vp19, han sido probados como blancos de dcARNs, debido a su abundancia en las partículas virales y a su importancia durante el proceso de infección en el hospedero (Sarathi et al., 2010; Mejía-Ruíz et al., 2011; Sudhakaran et al., 2011; Escobedo-Bonilla et al., 2015). No obstante, el bloqueo de la expresión de genes no estructurales como wsv191, wsv47, rr1, rr2, y orf89 también han mostrado gran potencial como tratamiento preventivo de la infección por WSSV (Escobedo-Bonilla et al., 2015; Rattanarojpong et al., 2016; Puneeth et al., 2017). 
A pesar de que los biofármacos de ARNi son una realidad a nivel experimental, los altos costos de producción de este tipo de moléculas constituyen uno de los principales obstáculos para lograr su aplicación a gran escala en granjas camaronícolas (Itsathitphaisarn et al., 2017). Sin embargo, la profilaxis con biofármacos de $\mathrm{ARNi}$, podría implementarse más fácilmente en las UPL, con el objetivo de prevenir cualquier contaminación con WSSV y otros agentes virales de preocupación que pudieran ocurrir durante el manejo de los reproductores (Flegel et al., 2019). Nuestros trabajos de investigación han demostrado que el silenciamiento con dcARN del gen correspondiente al orf89 disminuye considerablemente la replicación viral y la mortalidad del $100 \%$ al $10 \%$ en individuos $L$. vannamei adultos retados con WSSV, siendo similar a la mortalidad obtenida con el silenciamiento de genes estructurales vp28 (10\%) y vp26 (21\%) (Escobedo-Bonilla et al., 2015). En Penaeus monodon, se ha encontrado que ciertos individuos SPF pueden ser portadores asintomáticos y presentar una reactivación latente de la infección por WSSV bajo condiciones de estrés, relacionada con una alta expresión de ciertos genes virales, entre los cuales está el asociado al orf89 (también denominado wsv151) (Khadijah et al., 2003). El ARNm transcrito a partir del gen asociado al orf89 no sufre ningún proceso de edición y tiene un tamaño de 4,436 pb. La proteína deducida ORF89 tiene una longitud de 1,437 aminoácidos y un peso molecular de $165 \mathrm{kDa}$, y presenta dos señales de localización nuclear, así como un motivo de unión al ADN tipo zipper de leucina (Hossain et al., 2004). Ensayos de co-transfección en células Sf9 de insectos demostraron que ORF89 se localiza en el núcleo, donde actúa como represor del promotor de su propio gen, así como de los genes proteína cinasa ( $p k$ ) y timidina-timilidato cinasa (tk) del WSSV, los cuales son esenciales para la replicación y el establecimiento del estado de latencia del virus (Hossain et al., 2004). Ya que orf89 podría afectar la latencia y replicación del virus en cualquier edad del camarón (Hossain et al., 2004; Escobedo-Bonilla et al., 2015), este gen representa una opción viable para el diseño y construcción de un biofármaco de ARNi que genere protección específica contra el WSSV.

En el presente trabajo, se presentan resultados de la evaluación a pequeña escala de un biofármaco de ARNi basado en el silenciamiento del gen orf89 del WSSV con un dcARN específico, como antiviral profiláctico en reproductores de dos familias distintas de L. vannamei, las cuales fueron seleccionadas previamente por presentar cierto nivel de resistencia natural a la infección por WSSV.

\section{MATERIALES Y MÉTODOS}

\subsection{Animales}

Dos familias de camarones $L$. vannamei (B y C) de quinta generación (G5) producidas por la empresa Biomarina Reproductiva, S.A. de R.L. De C.V. en Sinaloa, México, fueron seleccionadas por mostrar resistencia natural y mayor supervivencia a la infección por WSSV. Camarones sanos de cada familia (B y C) en talla reproductora $(25-30 \mathrm{~g})$, fueron distribuidos en grupos de 10 individuos dentro de tinas $(100 \mathrm{~L})$ con agua marina filtrada $\left(28^{\circ} \mathrm{C}\right.$ y 35 UPS $)$ y bajo constante aireación. Los camarones se alimentaron dos veces al día con alimento comercial 
(35\% de proteína), equivalente al $3 \%$ de su peso corporal, y mantenidos en estas condiciones hasta el bioensayo.

\subsection{Preparación del biofármaco de ARNi (Bfvt)}

El biofármaco de ARNi (Bfvt) consiste en un ARN de doble cadena (dcARN) sintetizado mediante transcripción in vitro, el cual es capaz de activar los mecanismos de ARNi en las células del camarón para bloquear la expresión del gen orf89 del WSSV. Para sintetizar el dcARN, primeramente, se amplificó por PCR un fragmento (414 pb) del gen orf89 de 4311 pb (GenBank: AF369029.2, bases 128,334-132,644) (Marks et al., 2005). Esto se realizó utilizando como templado ADN del plásmido pCR2.1-TOPO (Thermo Scientific) con el fragmento del gen orf89 como inserto. Cada reacción de PCR $(25 \mu \mathrm{L})$ incluyó: 1X PCR buffer$\mathrm{Mg}, 1.6 \mu \mathrm{M}$ de $\mathrm{MgCl} 2,0.2 \mu \mathrm{M}$ de dNTPs, $0.5 \mu \mathrm{M}$ de primer ORF89 F1 (5'GAAGAAGCGCATGAATGACGC-3'), $0.5 \mu \mathrm{M}$ de primer ORF89 R1 (5'TCCTCCCCCTCCACAACTGC-3') (Álvarez-Sánchez et al., 2018), 0.5 U de Taq DNA polimerasa recombinante (Life Technologies) y $79 \mathrm{ng}$ de ADN plasmídico. Las condiciones de la PCR fueron: $94^{\circ} \mathrm{C}$ por 3 min $\left(1\right.$ ciclo); $94^{\circ} \mathrm{C}$ por $30 \mathrm{~s}, 59^{\circ} \mathrm{C}$ por $30 \mathrm{~s}$ y $72^{\circ} \mathrm{C}$ por $1 \mathrm{~min}$ ( 35 ciclos); $72^{\circ} \mathrm{C}$ por $10 \mathrm{~min}$ ( 1 ciclo). El producto de PCR primario fue posteriormente utilizado como templado en dos PCR separadas, con la finalidad de agregar una secuencia del promotor de la polimerasa del fago T7, tanto en orientación sentido ( $\left.5^{\prime}\right)$ como anti-sentido ( $\left.3^{\prime}\right)$. El fragmento sentido fue generado combinando los primers T7ORF89 F1 (5'GTAATACGACTCACTATAGGGGAAGAAGCGCATGAATGACGC-3') y ORF89 R1, mientras que los primers ORF89 F1 y T7ORF89 R1 (5'GTAATACGACTCACTATAGGGTCCTCCCCCTCCACAACTGC-3') se usaron para producir el amplicón anti-sentido. Ambas mezclas de reacción se elaboraron como se mencionó anteriormente, pero utilizando como ADN templado $1 \mu \mathrm{L}$ de producto de PCR primario diluido 1:100. Las condiciones de amplificación fueron idénticas a las anteriores. Ambos productos de PCR (sentido y anti-sentido) fueron purificados mediante precipitación con sulfato de amonio $3 \mathrm{M}(\mathrm{pH} 5.2)$ y 2.5 volúmenes de etanol absoluto. La pureza y el tamaño de los productos de PCR fue verificada mediante electroforesis en geles de agarosa (1.2\%) teñidos con GelRed 1X (Biotium).

Los productos de PCR del gen orf89 con el promotor T7 en orientación sentido y anti-sentido se utilizaron como ADN templado para sintetizar ARN de cadena sencilla (csARN) mediante transcripción in vitro con la ARN polimerasa del fago T7 según lo descrito en el kit T7 RiboMAX ${ }^{\mathrm{TM}}$ Express Large Scale RNA Production System (Promega). La concentración de cada csARN se determinó a partir de la absorbancia a $260 \mathrm{~nm}$ medida con un espectrofotómetro NanoPhotometer ${ }^{\circledR}$ P300 (IMPLEN). Las cadenas de csARN sentido y anti-sentido, al ser complementarias entre sí, se hibridaron para formar el dcARN anti-orf89, calentándolas a $80^{\circ} \mathrm{C}$ por 10 min para luego enfriarlas a temperatura ambiente. La formación del dcARN se confirmó mediante electroforesis en geles de agarosa (1.2\%) teñidos con GelRed 1X (Biotium). El Bfvt fue liofilizado en alícuotas de $200 \mu \mathrm{g}$ para su posterior preservación. Previo a los experimentos, se prepararon dosis individuales de $4 \mu \mathrm{g}$ de Bfvt en $40 \mu \mathrm{L}$ de solución amortiguadora de fosfato salino (PBS) 1X estéril. 


\subsection{Preparación de los inóculos virales}

Los inóculos virales utilizados en los ensayos de reto se obtuvieron a partir de camarones infectados naturalmente en una granja de camarón del sur de Sinaloa, los cuales se confirmaron positivos para WSSV por análisis PCR e histopatología. El concentrado viral se preparó a temperatura entre $4^{\circ} \mathrm{C}$ y $10^{\circ} \mathrm{C}$, mediante trituración de tejido branquial y pleópodos en solución amortiguadora TN (Tris$\mathrm{NaCl} \mathrm{pH}$ 7.4), seguido de aclaramiento por centrifugaciones diferenciales y filtración $(0.45 \mu \mathrm{m})$. A partir del producto resultante identificado como WSSV(I.V015), se prepararon 4 diluciones seriadas $\left(10^{-1}\right.$ a $\left.10^{-4}\right)$ y se distribuyó en alícuotas de $0.5,1.0$ y $2.0 \mathrm{~mL}$; las cuales se preservaron a $-70^{\circ} \mathrm{C}$ hasta su uso.

Para confirmar y evaluar la infectividad del inóculo viral a utilizar en los ensayos por infección intramuscular, así como para producir suficiente material biológicoinfeccioso (tejido infectado) para las infecciones por ingesta (per os), se realizaron ensayos preliminares y los organismos infectados fueron congelados para ser utilizados como alimento.

La dilución $10^{-4}$ con una carga viral de $1.31 \times 10^{3}$ copias virales/2 $\mu \mathrm{L}$ de ADN extraído, determinada por qPCR, fue utilizada para las infecciones vía intramuscular. Por otro lado, el inóculo preparado para las infecciones per os consistió en el tejido de camarón infectado con una carga viral de $8.22 \times 10^{3}$ copias virales/gramo de tejido proporcionado a los camarones como alimento y vehículo de infección. La determinación de las cargas virales fue realizada por qPCR de acuerdo con el protocolo indicado por el kit comercial IQ REAL ${ }^{T M}$ WSSV Quantitative system (GeneReach Biotechnology Corp., No. Cat: IQR-WSSV) (ver sección 2.5.).

\subsection{Bioensayo de reto con WSSV}

Los camarones de cada familia (120 por familia) fueron distribuidos en grupos de 8 individuos dentro de unidades experimentales de $40 \mathrm{~L}$ bajo las condiciones ambientales descritas anteriormente (ver sección 2.1.) Pasadas $24 \mathrm{~h}$, a cada camarón se le aplicó una sola dosis de Bfvt ( $4 \mu \mathrm{g} /$ organismo) mediante inyección intramuscular. Cumplidas $24 \mathrm{~h}$ desde la aplicación del Bfvt, se procedió a inocular a los camarones con WSSV, destinando una parte de los organismos de cada familia a infección por vía intramuscular (72 camarones por familia) y otra parte a infección per os (48 camarones por familia).

Los camarones de cada familia asignados a infección por vía intramuscular fueron inyectados con $100 \mu \mathrm{L}$ del inóculo viral (dilución $10^{-4}$ ) a través el tercer segmento abdominal. Como control negativo, un grupo de organismos recibió una inyección con $100 \mu \mathrm{L}$ de PBS, mientras que el control positivo consistió en camarones sin Bfvt pero inyectados con el inóculo viral. Cada tratamiento y grupo control consistió en 8 camarones, y se realizó por triplicado (24 camarones por tratamiento o control).

Para la infección per os, los organismos fueron dejados en ayuno por $24 \mathrm{~h} \mathrm{y}$ posteriormente alimentados con el material biológico-infeccioso. La alimentación con tejido infectado se realizó en dos ocasiones ( 0 y 24 h) en una proporción del 
$6 \%$ de la biomasa total en cada unidad experimental. Tres horas después de suministrado el tejido infectado se retiró el remanente por medio de sifoneo y se recuperó el nivel de agua perdido. Como control negativo, un grupo de camarones se alimentó con tejido no infeccioso (PCR negativo). El control positivo consistió en organismos sin Bfvt alimentados con el tejido infectado. Cada tratamiento y grupo control incluyó 8 camarones, y se realizó por duplicado (16 camarones por tratamiento o control).

El momento de la inoculación con WSSV, se tomó como el tiempo inicial del reto. Durante el bioensayo se realizaron observaciones y registros continuos para detectar cualquier cambio en el comportamiento, aparición de signos patognomónicos de WSSV, así como el tiempo transcurrido hasta la muerte. Los factores fisicoquímicos en las unidades experimentales se mantuvieron por debajo de niveles críticos (amonio total $<1.0 \mathrm{mg} / \mathrm{L}$; nitritos $<1.0 \mathrm{mg} / \mathrm{L}$; nitratos $\leq 20 \mathrm{mg} / \mathrm{L}$; $\mathrm{pH}$ 8; salinidad 34 UPS y temperatura controlada $27^{\circ} \mathrm{C} \pm 1^{\circ} \mathrm{C}$ ) con recambios de agua marina cada tercer día. Por otro lado, se mantuvieron estrictas medidas de bioseguridad de nivel 1 (BSL-1) (OMS, 2005) para evitar la diseminación de patógenos al medio ambiente. El reto viral fue detenido a las $144 \mathrm{hpi}$ y se colectaron muestras de tejido de branquia de los organismos sobrevivientes, las cuales fueron almacenadas a $-20{ }^{\circ} \mathrm{C}$ para detección de WSSV por PCR en tiempo real (qPCR).

\subsection{Detección y cuantificación de cargas virales}

La detección y cuantificación de WSSV en cada uno de los tratamientos se realizó a partir de muestras de branquias de los organismos sobrevivientes (144 hpi) del bioensayo de reto viral, las cuales fueron sometidas a qPCR, siguiendo el protocolo del kit comercial IQ REAL ${ }^{\mathrm{TM}}$ WSSV Quantitative System (GeneReach Biotechnology Corp.) que incluye los primers específicos WSS1011F (5'TGGTCCCGTCCTCATCTCAG-3') y WSS1079R (5'GCTGCCTTGCCGGAAATTA-3'), así como una sonda TaqMan $^{\circledR}$ (5'AGCCATGAAGAATGCCGTCTATCACACA-3'). Este sistema, permite detectar y cuantificar al patógeno, proporcionar un valor absoluto Qab, cantidad del blanco/ $\mu \mathrm{L}$ ) y reflejar el nivel de infección de un individuo. El número absoluto de copias virales se determinó a partir de una curva estándar de diluciones seriadas $\left(10^{0}-10^{6}\right.$ copias virales $\left./ \mu \mathrm{L}\right)$ del control positivo (estándar) del kit. La curva $\left(r^{2} \geq 0.99\right)$ se realizó por triplicado. Las muestras se analizaron en grupos de máximo 3 organismos por tratamiento, separando los organismos que presentaron signos de aquellos que no presentaron signos de infección por WSSV.

\subsection{Análisis estadísticos}

Los datos de mortalidad obtenidos durante el ensayo de reto viral fueron analizados estadísticamente mediante pruebas de probabilidad de supervivencia de Kaplan-Meier (Rich et al., 2010). Por otro lado, las diferencias entre familias (B y C) por tratamiento, así como el efecto del biofármaco sobre la supervivencia de los organismos en las dos vías de infección (intramuscular y per os), y con respecto a los controles (positivo y negativo), se establecieron mediante pruebas 
de Chi cuadrada $\left(\mathrm{X}^{2}\right)$. Los análisis estadísticos se realizaron con el Software Survival difference calculator (log rank test) (https://astatsa.com/LogRankTest/) con un nivel de significancia estadística de $p \leq 0.05$.

\section{RESULTADOS}

\subsection{Evidencias de infección y replicación viral}

Las dos familias evaluadas ( $\mathrm{B}$ y $\mathrm{C}$ ) mostraron buen estado de salud y comportamiento normal durante el periodo de aclimatación. No se presentaron mortalidades en los animales al ser tratados con Bfvt ni con la aplicación de PBS. Los signos de infección por WSSV fueron más frecuentes en camarones sin tratamiento con Bfvt (controles positivos de ambas familias), destacándose letargia, disminución en el consumo de alimento, cambios en la coloración corporal por expansión de cromatóforos, principalmente en urópodos (coloración "canelosa"), así como mortalidad.

La presencia de WSSV se detectó por medio de GPCR en los organismos sobrevivientes (144 hpi) del bioensayo de reto viral (Tabla 1). De acuerdo con los resultados, en el control positivo de la familia $B$ inoculado por vía intramuscular se detectó una carga viral de $2.87 \times 10^{4}$ copias virales/2 $\mu \mathrm{L}$ de $A D N$, mientras que en los organismos que recibieron Bfvt los valores fueron más bajos, de $2.42 \times 10^{1}$ $8.31 \times 10^{3}$ copias virales/2 $\mu \mathrm{L}$ de ADN. De manera similar, en el control positivo de la familia $C$ infectado por vía intramuscular se detectó una carga viral de $3.67 \times 10^{5}$ copias virales/2 $\mu \mathrm{L}$ de $\mathrm{ADN}$, al contrario de los organismos infectados y tratados con Bfvt que presentaron cargas virales "no detectables", es decir, por debajo del límite de detección por qPCR.

Por otro lado, el diagnóstico de los camarones de la familia B infectados vía per os reveló que el control positivo presentó una carga viral de $6.62 \times 10^{4}$ copias virales $/ 2 \mu \mathrm{L}$ de $\mathrm{ADN}$, mientras que en los camarones inyectados con Bfvt, las cargas virales fueron indetectables. En los camarones de la familia C (per os), las cargas virales en el control positivo también fueron mayores $\left(5.19 \times 10^{3}\right.$ copias virales $/ 2 \mu \mathrm{L}$ de $\mathrm{ADN}$ ) que las encontradas en los camarones infectados que recibieron el biofármaco $\left(7.54 \times 10^{2}\right.$ copias virales/2 $\mu \mathrm{L}$ de ADN a "no detectables"). Exceptuando los controles positivos, los organismos sobrevivientes de ambas familias no presentaron signos de infección, o estos fueron muy leves. Como se esperaba, no se detectó WSSV en las muestras de los controles negativos (sin infección). 
Tabla 2. Mortalidad (\%) registrada durante el bioensayo de reto viral.

Table 2. Mortality (\%) registered during the viral challenge bioassay.

\begin{tabular}{|c|c|c|c|c|c|c|c|}
\hline \multirow[t]{2}{*}{ Familia } & \multirow{2}{*}{$\begin{array}{ll}\text { Vía } & \text { de } \\
\text { infección }^{\varepsilon}\end{array}$} & \multirow[t]{2}{*}{ Tratamiento $\neq$} & \multicolumn{5}{|c|}{ Mortalidad (\%) } \\
\hline & & & $\begin{array}{l}24 \\
\text { hpi }\end{array}$ & $\begin{array}{l}48 \\
\text { hpi }\end{array}$ & $\begin{array}{l}72 \\
\text { hpi }\end{array}$ & $\begin{array}{l}120 \\
\text { hpi }\end{array}$ & $\begin{array}{l}144 \\
\text { hpi }\end{array}$ \\
\hline \multirow[t]{6}{*}{ B } & IM & Bfvt + WSSV & 0 & 16.6 & 20.83 & 29.1 & 29.1 \\
\hline & & + & 0 & 20.83 & 48.83 & 83.3 & 83.3 \\
\hline & & - & 0 & 0 & 0 & 0 & 0 \\
\hline & PO & Bfvt + WSSV & 0 & 6.25 & 25 & 43.75 & 50 \\
\hline & & + & 0 & 18.75 & 31.25 & 43.75 & 43.75 \\
\hline & & - & 0 & 0 & 0 & 0 & 0 \\
\hline \multirow[t]{6}{*}{ C } & IM & Bfvt + WSSV & 4.16 & 4.16 & 8.3 & 16.6 & 16.6 \\
\hline & & + & 0 & 16.6 & 41.6 & 75 & 83.3 \\
\hline & & - & 0 & 0 & 0 & 0 & 0 \\
\hline & $\mathrm{PO}$ & Bfvt + WSSV & 0 & 0 & 0 & 0 & 0 \\
\hline & & + & 0 & 0 & 12.5 & 31.25 & 37.5 \\
\hline & & - & 0 & 0 & 0 & 0 & 0 \\
\hline
\end{tabular}

£ Vía de infección per os (PO) e intramuscular (IM). ${ }^{¥}$ Tratamiento con biofármaco e infección (Bfvt + WSSV), control positivo con infección sin biofármaco (+), control negativo sin infección (-)

A)

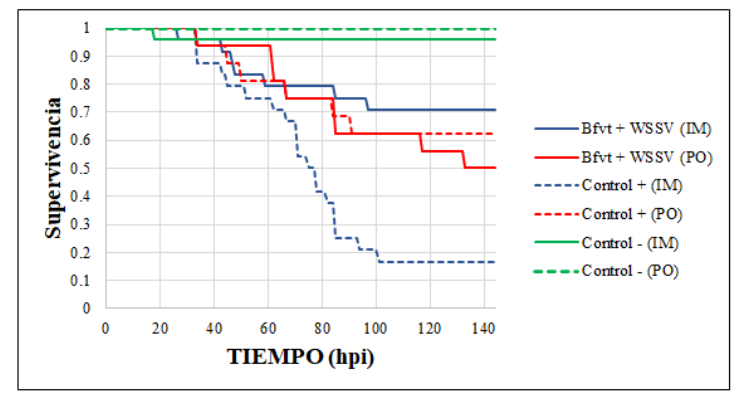

B)

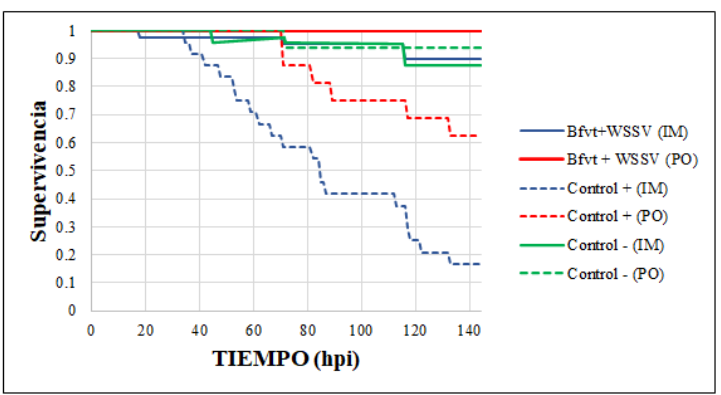

Fig. 1. Curva de supervivencia Kaplan-Meier de los diferentes tratamientos y controles del bioensayo de reto viral. A) Familia B; B) Familia C; IM, infección vía intramuscular; PO, infección vía per os; Bfvt + WSSV, tratamiento con biofármaco e infección; Control +, control positivo (infección sin biofármaco); Control -, control negativo (sin infección).

Fig.1. Kaplan-Meier survival curve for different controls and treatments from viral challenge bioassay. A) Family B; B) Family C; IM, intramuscular infection; PO, per os infection; Bfvt + WSSV, bio-drug + infection treatment; Control +, positive control (infection without bio-drug); Control -, negative control (without infection). 
Tabla 3. Comparación estadística por medio de la prueba $X^{2}$ entre las supervivencias encontradas en los tratamientos con Bfvt y controles positivos.

Table 3. Statistical comparison by $X^{2}$ test between the survival found in the treatments with Bfvt and positive controls.

\begin{tabular}{|c|c|c|c|c|c|}
\hline Familia & $\begin{array}{l}\text { Vía de } \\
\text { infección }\end{array}$ & $\begin{array}{l}\text { Comparación } \\
\text { tratamientos }\end{array}$ & $\mathbf{X}^{2}$ & $\mathbf{p}$ & $\begin{array}{l}\text { Diferencia } \\
\text { significativa }\end{array}$ \\
\hline \multirow[t]{2}{*}{ B } & IM & Bfvt + WSSV vs Control + & 5.29 & 0.0212 & $\mathrm{Si}$ \\
\hline & $\mathrm{PO}$ & Bfvt + WSSV vs Control + & 0.002 & 0.9605 & No \\
\hline \multirow[t]{2}{*}{ C } & IM & Bfvt + WSSV vs Control + & 7.26 & 0.0070 & Si \\
\hline & PO & Bfvt + WSSV vs Control + & 1.07 & 0.2993 & No \\
\hline
\end{tabular}

£ Vía de infección per os (PO) e intramuscular (IM). ${ }^{¥}$ Tratamiento con biofármaco e infección (Bfvt + WSSV), control positivo con infección sin biofármaco (+), control negativo sin infección (-).

Tabla 4. Comparación estadística por medio de la prueba $X^{2}$ entre las sobrevivencias encontradas en los tratamientos con Bfvt, controles positivos y controles negativos.

Table 4. Statistical comparison by $X^{2}$ test between the survival found in the treatments with Bfvt, positive controls, and negative controls.

\begin{tabular}{|c|c|c|c|c|c|}
\hline Familia & $\begin{array}{l}\text { Vía de } \\
\text { infección }^{\varepsilon}\end{array}$ & $\begin{array}{l}\text { Comparación } \\
\text { tratamientos }\end{array}$ & $\mathbf{X}^{2}$ & p & $\begin{array}{l}\text { Diferencia } \\
\text { significativa }\end{array}$ \\
\hline \multirow[t]{2}{*}{ B } & IM & Bfvt + WSSV vs Control - & 2.25 & 0.1330 & No \\
\hline & $\mathrm{PO}$ & $\begin{array}{l}\text { Control + vs Control - } \\
\text { Bfvt + WSSV vs Control - }\end{array}$ & $\begin{array}{l}7.93 \\
4.10\end{array}$ & $\begin{array}{l}0.0048 \\
0.0426\end{array}$ & $\begin{array}{l}\mathrm{Si} \\
\mathrm{Si}\end{array}$ \\
\hline \multirow[t]{3}{*}{ C } & IM & $\begin{array}{l}\text { Control + vs Control - } \\
\text { Bfvt + WSSV vs Control - }\end{array}$ & $\begin{array}{l}1.65 \\
0.20\end{array}$ & $\begin{array}{l}0.1985 \\
0.6520\end{array}$ & $\begin{array}{l}\text { No } \\
\text { No }\end{array}$ \\
\hline & $\mathrm{PO}$ & $\begin{array}{l}\text { Control + vs Control - } \\
\text { Bfvt + WSSV vs Control - }\end{array}$ & $\begin{array}{l}6.76 \\
0.73\end{array}$ & $\begin{array}{l}0.0093 \\
0.3921\end{array}$ & $\begin{array}{l}\mathrm{Si} \\
\text { No }\end{array}$ \\
\hline & & Control + vs Control - & 1.55 & 0.2123 & No \\
\hline
\end{tabular}

£ Vía de infección per os (PO) e intramuscular (IM). ${ }^{¥}$ Tratamiento con biofármaco e infección (Bfvt + WSSV), control positivo con infección sin biofármaco (+), control negativo sin infección (-).

No obstante, el biofármaco no tuvo el mismo efecto sobre la mortalidad (y supervivencia) de los organismos de la familia B inoculados con WSSV vía per os, ya que no hubo diferencias considerables en cuanto a la mortalidad entre los camarones infectados con y sin Bfvt (Tabla 2). El control positivo (sin Bfvt), alcanzó una mortalidad máxima de $43.75 \%$ a las $120 \mathrm{hpi}$, mientras que en aquellos organismos infectados e inyectados con Bfvt fue del $50 \%$ a las $144 \mathrm{hpi}$. 
En la familia $\mathrm{C}$, los camarones tratados con Bfvt no presentaron muertes, en contraste con el control positivo que acumuló una mortalidad máxima de $37.5 \%$ a las $144 \mathrm{hpi}$. La supervivencia a las $144 \mathrm{hpi}$ (Fig. 1) en las familias B y C tratadas con Bfvt e inoculadas por la vía per os fue de $56.25 \%$ y $100 \%$, respectivamente. Sin embargo, estos valores no fueron estadísticamente diferentes de los encontrados en los controles positivos (56.0 y $62.50 \%$ ) (Tabla 3). Por otro lado, al haber una mayor mortalidad en el tratamiento con Bfvt de la familia B, la supervivencia con respecto al control negativo también fue significativamente menor (Tabla 4), no así en la familia $C$, la cual no presentó diferencias significativas con el control sin infección. Así mismo, el control positivo de la infección por la vía per os sólo presentó diferencias con el control negativo en camarones de la familia B (Tabla 4).

La comparación estadística entre las supervivencias registradas para las familias B y C por tratamiento (Tabla 5), reveló que no existen diferencias significativas entre los controles positivos (con WSSV) de ambas familias, ni entre los grupos tratados con Bfvt y posteriormente inoculados con WSSV, ya sea por la vía intramuscular o per os.

Tabla 5. Comparación estadística por medio de la prueba $X^{2}$ entre las supervivencias obtenidas en los tratamientos de cada familia.

Table 5. Statistical comparison by $X^{2}$ test between the survival obtained in the treatments of each family.

\begin{tabular}{lllll}
\hline Vía de infección $^{\varepsilon}$ & Tratamiento $^{*}$ & $\mathbf{X}^{2}$ & $\mathbf{p}$ & $\begin{array}{l}\text { Diferencia } \\
\text { significativa }\end{array}$ \\
\hline IM & Bfvt + WSSV & 2.15 & 0.1417 & No \\
& Control + & 3.67 & 0.0552 & No \\
PO & Bfvt + WSSV & 0.46 & 0.4973 & No \\
& Control + & 1.58 & 0.2077 & No \\
\hline
\end{tabular}

¿ Vía de infección per os (PO) e intramuscular (IM). ${ }^{*}$ Tratamiento con biofármaco e infección (Bfvt + WSSV). Control positivo con infección de WSSV sin biofármaco (+).

\section{DISCUSIÓN}

La selección de familias con resistencia mejorada a enfermedades virales ha sido considerada una estrategia efectiva para disminuir los brotes infecciosos en la acuicultura de L. vannamei (Trang et al., 2019). Sin embargo, la supervivencia en familias seleccionadas de camarón blanco rara vez ha logrado rebasar el $50 \%$ en ensayos de reto viral (Huang et al., 2011; Cuéllar-Anjel et al., 2012; Trang et al., 2019). La baja supervivencia al WSSV se cree que se debe a una baja frecuencia de genes de resistencia en poblaciones naturales de camarón (Cock et al., 2009), dificultando lograr un nivel de resistencia que permita la independencia de otros métodos de prevención en condiciones de cultivo. Entre los métodos biotecnológicos que se encuentran en desarrollo para la prevención de enfermedades virales en la camaronicultura se encuentran los biofármacos de 
ARNi, los cuales potencialmente pueden inhibir infecciones por WSSV (Mejía-Ruiz et al., 2011; Álvarez-Ruiz et al., 2015; Chaimongkon et al., 2020). En el presente trabajo, mediante un ensayo de reto con WSSV por dos vías de inoculación (intramuscular y per os), se analizó el efecto de un biofármaco (Bfvt) de ARNi contra el gen orf89 del WSSV sobre la supervivencia de reproductores de camarón blanco pertenecientes a dos familias con cierta resistencia natural al virus.

La mortalidad causada por el WSSV fue mayor cuando se inoculó por inyección intramuscular comparado con la inoculación por ingesta, la cual no causó un número de muertes significativamente mayor al encontrado en los controles sin infección. La baja mortalidad causada por el inóculo per os pudo deberse a la falta de uniformidad en la carga viral ingerida de cada individuo, ya que al brindar el tejido infectado como alimento es difícil controlar la cantidad consumida por cada camarón (Escobedo-Bonilla et al., 2005). Por otro lado, la administración del inóculo por vía intramuscular permite que el virus evada algunas barreras físicas y fisiológicas antes de llegar a las células diana, al contrario de las partículas virales que ingresan por la cavidad oral que deben enfrentarse al ambiente hostil del tracto digestivo del camarón, marcado por cambios de $\mathrm{pH}$ y presencia de enzimas digestivas (Escobedo-Bonilla et al., 2006). Esto también podría explicar la falta de aumentos drásticos en la mortalidad acumulada en los grupos con infección per os, indicando una progresión lenta de la enfermedad.

La capacidad protectora del Bfvt contra el WSSV fue evidente en los camarones inoculados intramuscularmente en ambas familias, presentando en general cargas virales muy bajas y una mayor supervivencia a las $144 \mathrm{hpi}$, en comparación con los organismos que no recibieron Bfvt. El efecto fue notorio a partir de las $48 \mathrm{hpi}$, cuando la mortalidad se empezó a detener en los organismos tratados con biofármaco en comparación con los controles positivos. Las supervivencias obtenidas con el Bfvt al final del reto viral por inyección intramuscular $(70.9 \%$ B y $83.33 \% \mathrm{C})$, son similares a la reportada previamente $(90 \%, 108 \mathrm{hpi})$ en camarones L. vannamei inyectados con un dcARN contra el mismo gen (Escobedo-Bonilla et al., 2015). Estos hallazgos demuestran que, el silenciamiento del gen orf89 por ARNi es eficiente en inhibir este gen del WSSV, así como también otros genes estructurales (vp19, vp26, vp28) y no estructurales ( $r r 2$ y tk-tmk), con los cuales se han logrado supervivencias similares $(>70 \%)$ en ensayos de reto viral (Robalino et al., 2005; Escobedo-Bonilla et al., 2015; Kumar et al., 2015).

Con respecto a los organismos inoculados per os, la carga viral detectada en organismos infectados y tratados con Bfvt fue relativamente baja debido posiblemente al efecto del Bfvt. No obstante, de acuerdo con los análisis estadísticos $\mathrm{X}^{2}$, los efectos del biofármaco sobre la supervivencia no fueron significativos en los camarones de ambas familias, quizás por una menor capacidad infectiva del inóculo per os, lo que se traduce en una menor mortalidad acumulada con respecto al inóculo intramuscular. La vía de transmisión oral del WSSV ocurre naturalmente por canibalismo de camarones infectados, o por consumo de presas que actúan como vectores (Sánchez-Martínez et al., 2007). Por lo tanto, es importante validar la eficacia del Bfvt ante el WSSV inoculado vía per os. Dado que el desarrollo de la infección per os es más lento, se podría validar el efecto del Bfvt a mayor tiempo post inoculación, pues los dcARN pueden retener su capacidad antiviral hasta por 30 días (Mejía-Ruíz et al., 2011). En ese 
caso, para garantizar que los organismos reciban una carga viral uniforme, se podría utilizar un método de inoculación alternativo, por ejemplo, introduciendo el inóculo en el intestino a través de la cavidad oral con una pipeta delgada (Escobedo-Bonilla et al., 2006).

El ensayo de reto viral para validar la capacidad antiviral del Bfvt se realizó con camarones de talla reproductora $(>20 \mathrm{~g})$ seleccionados para pies de cría, que procedían de dos familias (B y C) con resistencia natural a WSSV. En los controles con infección, las cargas virales y la supervivencia no variaron significativamente de una familia a otra con los dos tipos de inoculo, sugiriendo que su nivel de resistencia al virus es similar. Sin embargo, la supervivencia fue menor en los grupos infectados intramuscularmente, con valores comparables con lo reportado en estudios de crianza selectiva de familias resistentes a WSSV. La mortalidad a 72 hpi en las familias B (48.8\%) y C (41.6\%) fue ligeramente menor que la documentada por Huang et al. (2011) para una familia G4 (52.22\% a 72 hpi) de L. vannamei, pero mayor a la reportada previamente para familias G2 (6.7-30.0\%) (Pan et al., 2008). Así mismo, la mortalidad máxima para las familias B y C (83.3\%) después de 6 días (144 hpi) fue similar a la determinada en una familia G3 (81\%) a los 5 días post inoculación con WSSV (Trang et al., 2019).

Por otro lado, la supervivencia entre familias en respuesta al tratamiento con Bfvt tampoco varió significativamente. No obstante, los organismos tratados con biofármaco de la familia $\mathrm{C}$ presentaron en general, cargas virales y mortalidades menores que la familia $\mathrm{B}$, independientemente de la vía de inoculación. Diversos componentes de la respuesta inmune innata intervienen en la resistencia a enfermedades virales en camarones, tales como la actividad fagocítica, el sistema pro-fenoloxidasa, proteínas de reconocimiento de patrones, péptidos antimicrobianos, mecanismos apoptóticos, la regulación de la expresión génica por ARNi, entre otros (Flegel \& Sritunyalucksana 2011; Underwood et al., 2014; Wang et al., 2014; Li et al., 2019). Con respecto a los mecanismos de ARNi en crustáceos, se ha demostrado que la inyección de dcARN tiene un efecto sistémico, siendo transportado el ARNi a distintos órganos a través de la hemolinfa (Robalino et al., 2007), donde no sólo es capaz de activar la maquinaria de interferencia, sino también la inmunidad innata no específica, incrementando la expresión y actividad del sistema pro-fenoloxidasa, proteínas de reconocimientos de patrones, enzimas hidrolíticas y antioxidantes (Dong et al., 2009; Maralit et al., 2015). La expresión de genes relacionados con estos mecanismos se ha reportado que puede variar entre familias de camarón blanco (Santos et al., 2021). Por lo tanto, sería interesante determinar si existen diferencias en la expresión de marcadores inmunológicos entre las familias B y C, tanto en respuesta a la infección por WSSV como a la administración profiláctica de Bfvt.

Finalmente, cabe mencionar que debido a los resultados positivos del Bfvt sobre la supervivencia a la infección por WSSV en reproductores, su aplicación intramuscular fue implementada en la UPL de la empresa Biomarina Reproductiva, S.A. de R.L. de C.V., como parte de un programa de manejo preventivo del WSSV a mayor escala, llevado a cabo en diciembre de 2020. El Bfvt se administró individualmente a 3,800 reproductores (talla $40 \pm 2 \mathrm{~g}$ ) con una mortalidad postaplicación del $0.5 \%$ y una supervivencia $3.7 \%$ mayor con respecto a los no tratados. Así mismo, la empresa reportó una producción de 300 millones de larvas 
a partir del lote de reproductores tratados con Bfvt, lo cual fue mayor a la producción de larvas a partir de reproductores que no fueron tratados con biofármaco.

En conclusión, el tratamiento con un dcARN específico contra el gen orf89 demostró ser una estrategia efectiva para inhibir la infección por WSSV. No obstante, debido a que, en términos de costo-beneficio el método de administración intramuscular es poco práctico para su aplicación masiva en granjas camaronícolas, actualmente se está trabajando en estrategias para abaratar y hacer más eficiente su producción. En ese sentido, nuestro grupo se encuentra desarrollando métodos de síntesis de dcARN in vivo (Álvarez-Sánchez et al., 2018). Esto a su vez permitirá investigar otros métodos de administración, por ejemplo, la inclusión en alimentos para camarón (Thammasorn et al., 2015).

\section{AGRADECIMIENTOS}

Los autores agradecen a Biomarina Reproductiva, S.A. de R.L. De C.V., Genética Acuícola Mexicana S.A. de C.V. (Genamex) y Comercializadora de Larvas Nauplios y Camarón S.A. de C.V. (Prolamar) por todas las facilidades brindadas para realizar este trabajo. Al M.C. René Rebollar Prudente (CIBNOR-La Paz) y a la IBQ. Alexia Guadalupe Audelo Fajardo (CIAD-Mazatlán) por su apoyo técnico.

\section{CONFLICTO DE INTERESES}

Los autores declaran que no existe conflicto de intereses.

\section{REFERENCIAS}

Alday-Sanz V. 2018. Specific pathogen free (SPF), specific pathogen resistant (SPR) and specific pathogen tolerant (SPT) as part of the biosecurity strategy for whiteleg shrimp (Penaeus vannamei Boone 1931). Asian Fisheries Science 31S: 112-120. https://doi.org/ 10.33997/j.afs.2018.31.s1.008

Alvarez-Ruiz P., Luna-González A., Escamilla-Montes R., Mejía-Ruiz C.H., Magallón-Barajas F. J., Llera-Herrera R. \& Galván-Alvarez D.A. 2015. Long-lasting effect against white spot syndrome virus in shrimp broodstock, Litopenaeus vannamei, by LvRab7 silencing. Journal of the World Aquaculture Society 46(6): 571-582. https://doi.org/10.1111/jwas.12236

Álvarez-Sánchez A.R., Romo-Quinones C., Rosas-Quijano R., Reyes A.G., Barraza A., Magallón-Barajas F., Angulo C. \& Mejía-Ruíz C.H. 2018. Production of specific ds RNA against white spot syndrome virus in the yeast Yarrowia lipolytica. Aquaculture Research 49(1): 480-491. https://doi.org/10.1111/are.13479

Arulmoorthy M.P., Anandajothi E., Vasudevan S. \& Suresh E. 2020. Major viral diseases in culturable penaeid shrimps: a review. Aquaculture International 28: 1939-1967. https://doi.org/10.1007/s10499-020-00568-3 
Benzie J.A. 2009. Use and exchange of genetic resources of penaeid shrimps for food and aquaculture. Reviews in Aquaculture 1(3-4): 232-250. https://doi.org/10.1111/j.1753-5131.2009.01018.x

Chaimongkon D., Assavalapsakul W., Panyim S. \& Attasart P. 2020. A multi-target dsRNA for simultaneous inhibition of yellow head virus and white spot syndrome virus in shrimp. Journal of Biotechnology 321: 48-56. https://doi.org/10.1016/j.jbiotec.2020.06.022

Chang P.S., Lo C.F., Wang Y.C. \& Kou, G.H. 1996. Identification of white spot syndrome associated baculovirus (WSBV) target organs in the shrimp Penaeus monodon by in situ hybridization. Diseases of aquatic organisms 27: 131-139. https://doi.org/10.3354/da0027131

Chakrobortty D., Ali M.R., Dey B.K., Gupta N., Islam S.S. \& Sui, L. 2020. Viral contamination of tiger shrimp Penaeus monodon broodstock in Bangladesh. Aquaculture International 28: 2161-2172. https://doi.org/10.1007/s10499-020$\underline{00583-4}$

Cock J., Gitterle T., Salazar, M. \& Rye, M. 2009. Breeding for disease resistance of Penaeid shrimps. $\quad$ Aquaculture 286(1-2): https://doi.org/10.1016/j.aquaculture.2008.09.011

Cuéllar-Anjel J., White-Noble B., Schofield P., Chamorro R. \& Lightner, D.V. 2012. Report of significant WSSV-resistance in the Pacific white shrimp, Litopenaeus vannamei, from a Panamanian breeding program. Aquaculture 368: 36-39. https://doi.org/10.1016/j.aquaculture.2012.08.048

Dong C., Zhao J., Song L., Wang L., Qiu L., Zheng P., Li L., Gai Y. \& Yang, G. 2009. The immune responses in Chinese mitten crab Eriocheir sinensis challenged with double-stranded RNA. Fish \& Shellfish Immunology 26(3): 438-442. https://doi.org/10.1016/j.fsi.2009.01.005

Escobedo-Bonilla C.M., Wille M., Sanz V.A., Sorgeloos P., Pensaert M.B. \& Nauwynck, H.J. 2005. In vivo titration of white spot syndrome virus (WSSV) in specific pathogen-free Litopenaeus vannamei by intramuscular and oral routes. Diseases of Aquatic Organisms 66: 163-170. https://orcid.org/10.3354/dao066163

Escobedo-Bonilla C.M., Audoorn L., Wille M., Alday-Sanz V., Sorgeloos P., Pensaert M.B. \& Nauwynck, H.J. 2006. Standardized white spot syndrome virus (WSSV) inoculation procedures for intramuscular or oral routes. Diseases of Aquatic Organisms 68: 181-188. https://orcid.org/10.3354/dao068181

Escobedo-Bonilla C.M., Alday-Sanz V., Wille M., Sorgeloos P., Pensaert M.B. \& Nauwynck H.J. 2008. A review on the morphology, molecular characterization, morphogenesis and pathogenesis of white spot syndrome virus. Journal of fish diseases 31: 1-18. https://doi.org/10.1111/j.1365-2761.2007.00877.x 
Escobedo-Bonilla C.M., Vega-Peña S. \& Mejía-Ruíz C.H. 2015. Efficacy of doublestranded RNA against white spot syndrome virus (WSSV) non-structural (orf89, wsv191) and structural (vp28, vp26) genes in the Pacific white shrimp Litopenaeus vannamei. Journal of King Saud University-Science 27(2): 182-188. https://doi.org/10.1016/j.jksus.2014.11.004

Flegel T \& K. Sritunyalucksana. 2011. Shrimp Molecular Responses to Viral Pathogens. Mar. Biotech. 13:4, 587-607. Doi: 10.1007/s10126-010-9287-x

Flegel T.W. 2019. A future vision for disease control in shrimp aquaculture. Journal of the World Aquaculture Society 50(2): 249-266. https://doi.org/10.1111/jwas.12589

Gong, Y. \& Zhang, X. 2021. RNAi-based antiviral immunity of shrimp. Developmental \& Comparative Immunology 115: 103907. https://doi.org/10.1016/..dci.2020.103907

Hossain M.S., Khadijah S. \& Kwang, J. 2004. Characterization of ORF89-a latency-related gene of white spot syndrome virus. Virology 325(1): 106-115. https://doi.org/10.1016/.j.virol.2004.05.005

Huang Y.C., Yin Z.X., Ai H.S., Huang X.D., Li S.D., Weng S.P. \& He J.G. 2011. Characterization of WSSV resistance in selected families of Litopenaeus vannamei. Aquaculture 311(1-4): https://doi.org/10.1016/j.aquaculture.2010.11.032

Itsathitphaisarn O., Thitamadee S., Weerachatyanukul W. \& Sritunyalucksana K. 2017. Potential of RNAi applications to control viral diseases of farmed shrimp. Journal of Invertebrate Pathology 147: 76-85. https://doi.org/10.1016/j.jip.2016.11.006

Khadijah S., Neo S.Y., Hossain M.S., Miller L.D., Mathavan S. \& Kwang J. 2003. Identification of white spot syndrome virus latency-related genes in specificpathogen-free shrimps by use of a microarray. Journal of virology, 77: 1016210167. https://doi.org/10.1128/jvi.77.18.10162-10167.2003

Kumar A., Laramore S., Alexander P., Allnutt F.T. \& Sayre, R.T. 2015. Double Stranded RNA Simultaneously Targeting four White Spot Syndrome Virus (WSSV) genes provides protection against WSSV in Litopenaeus vannamei. International Journal of Marine Science and Ocean Technology 2(2): 5-10.

Li C., Weng S. \& He J. 2019. WSSV-host interaction: Host response and immune evasion. Fish \& Shellfish Immunology 84: 558-571. https://doi.org/10.1016/j.fsi.2018.10.043 
Marks H., van Duijse J.J., Zuidema D., van Hulten M.C. \& Vlak J.M. 2005. Fitness and virulence of an ancestral White Spot Syndrome Virus isolate from shrimp. Virus Resesearch 110: 9-20. https://doi.org/10.1016/..virusres.2005.01.002

Maralit B.A., Komatsu M., Hipolito S.G., Hirono I. \& Kondo, H. 2015. Microarray analysis of immunity against WSSV in response to injection of non-specific long dsRNA in kuruma shrimp, Marsupenaeus japonicus. Marine Biotechnology 17: 493-501. https://doi.org/10.1007/s10126-015-9637-9

Mejía-Ruíz C.H., Vega-Peña S., Alvarez-Ruiz P. \& Escobedo-Bonilla C.M. 2011. Double-stranded RNA against white spot syndrome virus (WSSV) vp28 or vp26 reduced susceptibility of Litopenaeus vannamei to WSSV, and survivors exhibited decreased susceptibility in subsequent re-infections. Journal of Invertebrate Pathology 107(1): 65-68. https://doi.org/10.1016/j.jip.2011.02.002

Nguyen D.V., Christiaens O., Bossier P. \& Smagghe G. 2018. RNA interference in shrimp and potential applications in aquaculture. Reviews in Aquaculture 10(3): 573-584. https://doi.org/10.1111/raq.12187

OMS. 2005. Manual de bioseguridad en el laboratorio. Organización Mundial de la Salud. Ginebra, Suiza. pp. 2010.

Pan Z.C., He J.G., Weng S.P., Yin Z.X., Fu X.Z. \& Li, S.D. 2008. Changes in mortality and immunological variables of Litopenaeus vannamei parents and their filial families infected with white spot syndrome under different experimental conditions. Fish \& Shellfish Immunology 25(5): 459-471. https://doi.org/10.1016/j.fsi.2008.02.003

Puneeth T.G., Akhila D.S., Dechamma M.M., Shreeharsha J.M., Shivakumar S.K. \& Venugopal M.N. 2017. Comparative Efficacy of dsRNA VP24, VP26, RR1 and WSV477 Gene against WSSV Infection in Penaeus monodon. International Journal of Current Microbiology and Applied Sciences 6(2): 665-674.

Rattanarojpong T., Khankaew S., Khunrae P., Vanichviriyakit R. \& Poomputsa K. 2016. Recombinant baculovirus mediates dsRNA specific to rr2 delivery and its protective efficacy against WSSV infection. Journal of Biotechnology 229: 44-52. https://doi.org/10.1016/j.jbiotec.2016.05.007

Rich J.T., Neely J.G., Paniello R.C., Voelker C.C. Nussenbaum B. \& Wang E.W. 2010. A practical guide to understanding Kaplan-Meier curves. OtolaryngologyHead and Neck Surgery. 143(3): 331-336. https://doi.org/10.1016/i.otohns.2010.05.007

Robalino J., Bartlett T., Shepard E., Prior S., Jaramillo G., Scura E., Chapman R.W., Gross P.S., Browdy C.L. \& Warr G.W. 2005. Double-Stranded RNA Induces Sequence-Specific Antiviral Silencing in Addition to Nonspecific Immunity in a Marine Shrimp: Convergence of RNA Interference and Innate Immunity in the 
Invertebrate Antiviral Response?. Journal of Virology 79: 13561-13571 https://doi.org/10.1128/JVI.79.21.13561-13571.2005

Rodriguez-Anaya L.Z., Gonzalez-Galaviz J.R., Casillas-Hernandez R., Lares-Villa F., Estrada K., Ibarra-Gamez J.C., \& Sanchez-Flores A. 2016. Draft genome sequence of white spot syndrome virus isolated from cultured Litopenaeus vannamei in Mexico. Genome announcements 4: e01674-15. https://orcid.org/10.1128/genomeA.01674-15

Sánchez-Martínez J.G., Aguirre-Guzmán G. \& Mejía-Ruíz, H. 2007. White spot syndrome virus in cultured shrimp: a review. Aquaculture Research 38(13): 13391354. https://doi.org/10.1111/j.1365-2109.2007.01827.x

Santos C.A., Andrade S.C., Teixeira A.K., Farias F., Guerrelhas A.C., Rocha J.L. \& Freitas P.D. 2021. Transcriptome differential expression analysis reveals the activated genes in Litopenaeus vannamei shrimp families of superior growth $\begin{array}{llll}\text { performance. } & \text { Aquaculture } & 735871 \text { : }\end{array}$ https://doi.org/10.1016/i.aquaculture.2020.735871

Sarathi M., Simon M.C., Venkatesan C., Thomas J., Ravi M., Madan N., Thiyagarajan S. \& Sahul Hameed A.S. 2010. Efficacy of bacterially expressed dsRNA specific to different structural genes of white spot syndrome virus (WSSV) in protection of shrimp from WSSV infection. Journal of Fish Diseases 33: 603-607. https://doi.org/10.1111/j.1365-2761.2010.01157.x

Seibert C.H. \& Pinto A.R. 2012. Challenges in shrimp aquaculture due to viral diseases: distribution and biology of the five major penaeid viruses and interventions to avoid viral incidence and dispersion. Brazilian Journal of Microbiology 43(3): 857-864. https://doi.org/10.1590/S1517-83822012000300002

Shekar M., Pradeep B. \& Karunasagar I. 2012. White spot syndrome virus: genotypes, epidemiology and evolutionary studies. Indian Journal of Virology 23: 175-183. https://doi.org/10.1007/s13337-012-0078-z

Sudhakaran R., Mekata T., Kono T., Inada M., Okugawa S., Yoshimine M., Yoshida T., Sakai M. \& Itami T. 2011. Double-stranded RNA-mediated silencing of the white spot syndrome virus VP28 gene in kuruma shrimp, Marsupenaeus japonicus. Aquaculture Research 42(8): 1153-1162. https://doi.org/10.1111/j.13652109.2010.02703.x

Thammasorn, T., Sangsuriya P., Meemetta W., Senapin S., Jitrakorn S., Rattanarojpong T. \& Saksmerprome V. 2015. Large-scale production and antiviral efficacy of multi-target double-stranded RNA for the prevention of white spot syndrome virus (WSSV) in shrimp. BMC biotechnology 15: 1-7. https://doi.org/10.1186/s12896-015-0226-9 
Trang T.T., Hung N.H., Ninh N.H., Knibb W. \& Nguyen N.H. 2019. Genetic variation in disease resistance against White Spot Syndrome Virus (WSSV) in Litopenaeus vannamei. Frontiers in Genetics 10: 264. https://doi.org/10.3389/fgene.2019.00264

Underwood D.J., Cowley J.A. \& Johnson, K.N. 2013. Antiviral immunity and protection in penaeid shrimp. Invertebrate Immunity 1: 2-14. https://doi.org/10.2478/invim-2013-0001

Wang P.H., Huang T., Zhang X. \& He J.G. 2014. Antiviral defense in shrimp: from innate immunity to viral infection. Antiviral Research 108: 129-141. https://doi.org/10.1016/j.antiviral.2014.05.013 